\title{
Multi-objective Optimization in CNC Turning Process using Taguchi Method
}

\author{
K. Kushal Kumar', Asst. Prof. Gangadhar Biradar², Asst. Prof. MD. Ashfaq Hussain ${ }^{3}$ \\ PG Student, Mechanical Engineering (CIM), GND Engineering College, Bidar, India ${ }^{1}$ \\ Assistant Professor, Mechanical Engineering, GND Engineering College, Bidar, India ${ }^{2,3}$
}

\begin{abstract}
Machining process is the most important operations in many manufacturing industries. One of the important parts of machining is turning process. Turning is a manufacturing process where the excess of material is removed from the work-piece. Machining process consists of characteristics such as surface roughness, material removal rate and accuracy which will determine the quality of the product. The quality of the product is dependent on surface roughness, where as the material removal rate will determine the rate of productivity and the accuracy will give the dimensional tolerance. These characteristics are dependent on the factors such as speed, feed and depth of cut turning operation is one of the most basic machining processes. Turning can generally be done both on the inner and outer surface. The starting material is a work-piece which is generated by other process such as casting, forging, extrusion or drawing. Proper setting of cutting parameters is important to obtain the better surface finish, accuracy and material removal rate. Unfortunately, conventional trial and error method is most time consuming and requires high cost. The purpose of this study is to determine the most significant parameters and its optimum range in CNC turning using various statistical tools such as Analysis of Variance (ANOVA).
\end{abstract}

Keywords: Turning operation, Analysis of Variance (ANOVA), Signal to Noise Ratio (SN).

\section{INTRODUCTION}

One of the most significant developments in production engineering over the last 20 years is the application of numerically controlled machine tools in production. There is no doubt that the CNC application first started with "AEROSPACE" Industries to manufacture highly complex parts that are made up of light alloys, having a heavy material removal. The CNC machine tools today have made considerable in road, to medium and large batch production in many metal working industries. The capital cost of CNC machines is relatively high, further to be justified only by the "AEROSPACE" industries, it is now being accepted by other industries because of numerous direct and indirect benefits driven by their applications.

One of the most distinct advantages of CNC machining over conventional machining is the elimination of multiple setup and high human skill for the control of machine functions. Other notable advantages in production using CNC includes the flexibility to machine a variety of work pieces in small and medium batches, saving in floor space, elimination of several stages of inspection, reduction in machining time reduction of work in progress and reduction in the requirements of special tools and gauges, besides improved accuracy and repeatability of machined components.

The figure below shows the turning process.

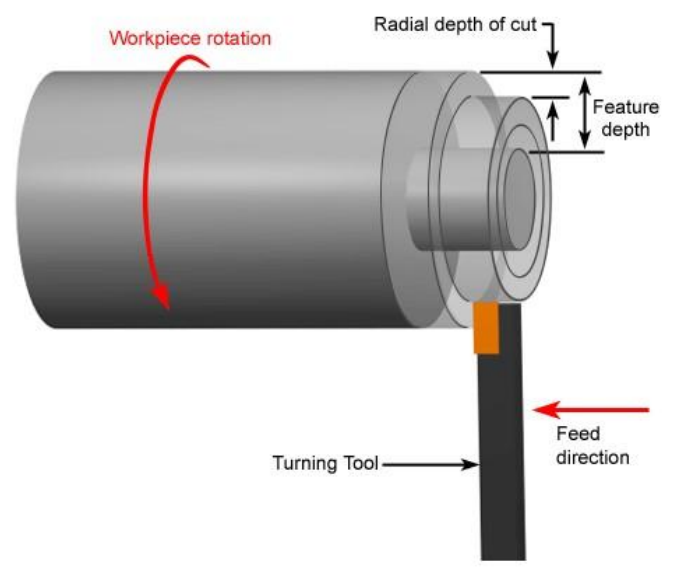

Figure 1.1 Turning Process. 
In the field manufacturing parameters optimization a large number of techniques have been implemented. Optimization problem includes process engineering, product design and quality control process planning and different machining operations numerically or conventionally controlled. The optimization problem can be differentiated into single or multi-objective, depending on the number of its quality targets. When dealing with machining optimization problems, quality characteristics are usually more than one, due to high process complexity. The overall goal is to find solutions that are acceptable by the decision maker. Multi-objective ones provide users with sets of solutions, out of which one should be chosen so as to apply in physical system where as in single- objective optimization problems; it is straightforward to find an optimal solution.

\subsection{ANALYSIS OF VARIANCE (ANOVA):}

Analysis of Variance or ANOVA is a statistical technique that consists of differentiating the observed variance into different techniques to conduct various significant examinations. Here we are going to applications of ANOVA to a set of data that consists of independent variables and examine whether a linear relationship exists between dependent variable and independent variable using ANOVA.

\subsubsection{SUM OF SQUARE AND MEAN SQUARE:}

The total variance of an observed data set can be obtained using following relationship.

Where, $\mathrm{S} \rightarrow$ standard deviation

$$
\mathrm{S}^{2}=\frac{\sum_{\mathrm{i}=0}^{\mathrm{n}}\left(\mathrm{y}_{\mathrm{i}}-\overline{\mathrm{y}}\right)^{2}}{\mathrm{n}-1}
$$

$\mathrm{y} \rightarrow \mathrm{i}^{\text {th }}$ observation

$\mathrm{n} \rightarrow$ number of observations

$\overline{\mathrm{y}} \rightarrow$ Mean of $\mathrm{n}$ observations

The value of numerator in the given equation is called as the Sum of Square. It is given as sum of square of all deviation of the observationsy $y_{i}$, from the mean of the observations i.e. $\bar{y}$. In the condition of ANOVA, this value is named as total sum of square as it is related to the total variance of the observations. Hence

$$
\mathrm{SS}_{\mathrm{T}}=\sum_{\mathrm{i}=0}^{\mathrm{n}}\left(\mathrm{y}_{\mathrm{i}}-\overline{\mathrm{y}}\right)^{2}
$$

In the above equation of the Sum of Square, the denominator shows the degree of freedom of sample variance. Therefore the degree of freedom associated with the Sum of Square is $\mathrm{SS}_{\mathrm{T}}$, is $(\mathrm{n}-1)$. Here the sample variance is also related to the Mean Square as it is obtained by dividing the Sum of Square by the degree of freedom.

$$
\mathrm{MS}_{\mathrm{T}}=\frac{\mathrm{SS}_{\mathrm{T}}}{\operatorname{dof}\left(\mathrm{SS}_{\mathrm{T}}\right)}
$$

Here the denominator of the above Mean Square equation is given as the Degree of Freedom of the Sum of Square.

\section{LITERATURE SURVEY}

Ranganath M.S. et. al. (2015) "optimized surface roughness in CNC Turning of Aluminium 6061 using Taguchi technique". In this study he used Aluminium 6061 to conduct the experiment on turning. The experiments were carried out in dry condition without any use of lubrication. Surface roughness is the main quality function in high speed turning of Aluminium 6061 in dry conditions. In this study, the effect and optimization of machining parameters (cutting speed, feed rate and depth of cut) on surface roughness is investigated. An L27 orthogonal array, analysis of variance (ANOVA) and the signal-to-noise ratio are used in this study. Three levels of machining parameters are used and experiments are done on LMW LL20TL3 CNC lathe. From the experiment he showed that speed, depth of cut and feed rate are significantly at $95 \%$ confident level and thus affecting the mean value and variation around the mean value of surface roughness. He concluded that speed is the most significant factor affecting surface roughness followed by depth of cut. [1]

Nikunj V. Patel. et. al. (2012) Focus his study on the "selection of tool insert in CNC Turning process using MADM method". In this study he conducted the experiment on the steel alloy. Surface roughness is the main response that is being examined in this experiment. In this study the main factors that are affecting the machining parameters are feed rate, cutting speed, depth of cut, cutting fluid and insert radius of the tool. This experiment is conducted in the presence of fluid which acts as a coolant and carries away the heat of work-piece chips that are removed. The analysis is done using Multiple Attribute Decision-Making (MADM) which consists of 2 methods that are Simple Additives Weighting (SAW) and Weighted Product Method (WPM). Here 5 different levels of tool insert angles are used in the experiment, so the tools angle of inclination is $0.40,0.25,0.20,0.10 \& 0.05$. From the experiment it is found that the tool with 0.20 angle of inclination gives higher surface finish.. [2] 
Krupal Pawar. et. al. (2016) performed "multi-objective optimization of CNC Turning Process parameters for High Speed Steel (M2) using Taguchi and ANOVA method". In this study he used Speed Steel (M2) to conduct the experiment. The experiment was carried out in dry condition without any use of lubrication. In this study the main factors that are affecting the machining parameters are feed rate, cutting speed, depth of cut, insert nose radius with constant spindle speed of 2800rpm. The main responses of the experiment are Surface roughness (Ra) \& Material Removal Rate (MRR). An L9 orthogonal array, Taguchi method and analysis of variance (ANOVA) are used in this study. Three levels of machining parameters are used and experiments are done on ECOCA-3807 CNC lathe. Minitab 14 software is used for the analysis in the experiment. In the experiment it is found that improvements in response characteristics such as Surface roughness (Ra) \&Material Removal Rate (MRR) are 71.06\% \& 69.36\% respectively due to process optimization. [3]

G.Hainath Gowd. et. at. (2014) "Optimised the machining parameters in CNC turning process of EN-31 using intelligent hybrid decision making tool". Here EN-31 work-piece material is used to conduct the experiment. In this study, the effect and optimization of machining parameters (cutting speed, feed rate and depth of cut) on surface roughness is investigated. The responses that are to be examined in this experiment are Surface Roughness and dimensional tolerance. Force and temperature are the outputs parameters of the experimentation. Three levels of machining parameters are used and experiments are done on CNC turning lathe. An Artificial Neural Network (ANN), analysis of variance (ANOVA) is used as the statistical tools. From the experiment it is found that speed and depth of cut have great significance on force and temperature, where as feed has less significance on both the output. [4]

D.M. D'Addona. et. at. (2015) “Analysed the surface roughness in hard turning using wiper insert geometry". The experiment is carried out by using the OHNS Steel of size 50mm length \& 40mm diameter as the work-piece material. The main machining parameters that are considered in this experiment are speed, feed, depth of cut and nose radius. The experiment is carried to study the performance of wiper insert in terms of surface finish. An L36 orthogonal array, analysis of variance (ANOVA) and Analysis of means (AOM) are used in the study. Three levels of machining parameters are used of which Conventional method consists of 1 level and Wiper method consists of 2 levels and the experiments are done on CNC turning lathe. Minitab- 16 is used for optimization of parameters. In this experiment the surface roughness data showed that feed, depth of cut and type of insert are the statistical significant parameters which effects surface roughness. [5]

Basil M. Eldhose. et. at. (2014) “Optimized of cutting parameters of SS 304 for CNC turning operation”. In the study he used SS 304 work-piece material to conduct the experiment. In this study, the effect and optimization of machining parameters (cutting speed, feed rate and depth of cut) on surface roughness is investigated. The main responses that are to be examined here are Material Removal Rate (MRR) and Surface Roughness (Ra). Taguchi method is used for designing of the experiment. An L9 orthogonal array, analysis of variance (ANOVA) and the signal-to-noise ratio are used in this study. Nine levels of machining parameters are used and experiments are done on CNC turning lathe. Minitab 16 software is used for the generation of orthogonal array in the experiment. In this study the regression equation is used for optimizing the output parameters for any machine with different combination of input parameters. [6]

Nand Kumar. et. al. (2014) "Monitored surface finish in CNC Turning using RSM and Taguchi Technique. In the study he used Aluminium (KS 1275) work-piece material to conduct the experiment. In this study, the effect and optimization of machining parameters (cutting speed, feed rate and depth of cut) on surface roughness is investigated. An L27 orthogonal array, analysis of variance (ANOVA), central composite design (CCD) and the signal-to-noise ratio are used in this study. Three levels of machining parameters are used and experiments are done on LT2 XL CNC lathe. Version 15 of the Minitab was used to develop the experiment plan for Taguchi response surface methodology \& for data collection. The experiment shows that feed rate is the most significant factors followed by depth of cut $\&$ speed. [7]

Vitor Augusto A.de Godoy. et. al. (2013) has studied the "turning of interruption and continuous hardened steel surface using ceramics and CBN cutting tools". In the study hardened steel of AISI 4340 steel with 56HRC is used as workpiece material to conduct the experiment and the tools used are CNB of codes $7015 \& 7025$ and ceramics. In this study, the effect and optimization of machining parameters are cutting speed, continuous cutting and interrupted cutting on surface roughness is investigated. Eight levels of machining parameters are used and experiments are done on CNC turning lathe of $15 \mathrm{kw}$ of power in the spindle motor. The main responses that are to be examined here are tool life and Surface Roughness (Ra). An EDS (energy dispersive X-ray spectroscopy) analysis technique is used in the experimentation. Flank wear and material removal rate are the parameters of the inspection of tool. In the experiment it is shown that CNB tools have the longer tool life than that if ceramics, as the reason for this is because they are hot hardened. [8] 


\section{EXPERIMENTAL SETUP AND DESIGN}

3.1 SELECTION OF PARAMETERS FOR TURNING EXPERIMENT: The parameters that we are selecting are mainly based on the literature survey. As from the literature we have found that the effecting parameters are speed, feed, depth of cut and nose radius. From these parameters the most effecting are the speed feed and depth of cut, and these are the parameters that can be easily deviated so that we can get the optimized responses that are the Surface roughness (Ra) and Material Removal Rate (MRR).

The selection of the levels of the input parameters is very important. This selection will define the output parameters which will affect the result of the experiment. The selection of parameters has to be carried out according to the standards. A standard range of parameters levels have been obtained from the "Manufacturing \& Operational Management "book, where a range for the input parameters has been mentioned. For the output parameters to be optimum we have select the levels of the parameters form this range. The levels with which the experiment has been carried out is given below. The table below shows the parameters and the levels that we are taking into account to conduct the experiment.

Table No 4.3- Parameters and levels of Experiment.

\begin{tabular}{|c|c|c|c|c|}
\hline \multirow{2}{*}{ PARAMETERS } & \multicolumn{4}{|c|}{ LEVELS } \\
\cline { 2 - 5 } & 1 & 2 & 3 & 4 \\
\hline Speed $(\mathrm{rpm})$ & 3000 & 3200 & 3400 & 3600 \\
\hline Feed $(\mathrm{mm} / \mathrm{rev})$ & 0.06 & 0.08 & 0.10 & 0.12 \\
\hline DOC $(\mathrm{mm})$ & 0.20 & 0.25 & 0.30 & 0.35 \\
\hline
\end{tabular}

\subsection{DESIGN OF THE EXPERIMENT:}

\section{No of parameters $=3$}

No of levels for each parameters $=4$

Total degree of freedom for 3 parameters $=3 \mathrm{x}(4-1)=9$

Therefore the minimum no of experiments $=$ total DOF for parameters $+1=9+1=10$

Therefore minimum no of experiments $=10$.

As we have 3 factors and 4 levels in the experiment, so L16 orthogonal array of Taguchi is to be selected. The table below shows the L16 orthogonal array.

Table No 4.4- Taguchi’s L16 Orthogonal Array.

\begin{tabular}{|c|c|c|c|c|c|}
\hline \multirow{2}{*}{ Expt. No } & \multicolumn{5}{|c|}{ Column } \\
\cline { 2 - 6 } & 1 & 2 & 3 & 4 & 5 \\
\hline 1 & 1 & 1 & 1 & 1 & 1 \\
\hline 2 & 1 & 2 & 2 & 2 & 2 \\
\hline 3 & 1 & 3 & 3 & 3 & 3 \\
\hline 4 & 1 & 4 & 4 & 4 & 4 \\
\hline 5 & 2 & 1 & 2 & 3 & 4 \\
\hline 6 & 2 & 2 & 1 & 4 & 3 \\
\hline 7 & 2 & 3 & 4 & 1 & 2 \\
\hline 8 & 2 & 4 & 3 & 2 & 1 \\
\hline 9 & 3 & 1 & 3 & 4 & 2 \\
\hline 10 & 3 & 2 & 4 & 3 & 1 \\
\hline 11 & 3 & 3 & 1 & 2 & 4 \\
\hline 12 & 3 & 4 & 2 & 1 & 3 \\
\hline 13 & 4 & 1 & 4 & 2 & 3 \\
\hline 14 & 4 & 2 & 3 & 1 & 4 \\
\hline 15 & 4 & 3 & 2 & 4 & 1 \\
\hline 16 & 4 & 4 & 1 & 3 & 2 \\
\hline
\end{tabular}

The table below shows the factors allotment to the column by using Linear Graph, based on this we have conducted the experiments. 
UGC Approved Journal

Table No 4.5-Parameters of the Experiment according to L16 Orthogonal Array.

\begin{tabular}{|c|c|c|c|c|c|}
\hline \multirow{2}{*}{$\begin{array}{c}\text { Expt. } \\
\text { No }\end{array}$} & \multicolumn{5}{|c|}{ Column } \\
\cline { 2 - 6 } & Spindle speed (rpm) & $\begin{array}{c}2 \\
\text { Feed rate }(\mathrm{mm} / \mathrm{rev})\end{array}$ & $\begin{array}{c}3 \\
\text { Depth of cut }(\mathrm{mm})\end{array}$ & $\begin{array}{c}4 \\
(\mathrm{e})\end{array}$ & $\begin{array}{c}5 \\
(\mathrm{e})\end{array}$ \\
\hline 1 & 3000 & 0.06 & 0.20 & 1 & 1 \\
\hline 2 & 3000 & 0.08 & 0.25 & 2 & 2 \\
\hline 3 & 3000 & 0.10 & 0.30 & 3 & 3 \\
\hline 4 & 3000 & 0.12 & 0.35 & 4 & 4 \\
\hline 5 & 3200 & 0.06 & 0.25 & 4 & 3 \\
\hline 6 & 3200 & 0.08 & 0.20 & 1 & 2 \\
\hline 7 & 3200 & 0.10 & 0.35 & 2 & 1 \\
\hline 8 & 3200 & 0.12 & 0.30 & 4 & 2 \\
\hline 9 & 3400 & 0.06 & 0.35 & 3 & 1 \\
\hline 10 & 3400 & 0.08 & 0.20 & 2 & 4 \\
\hline 11 & 3400 & 0.10 & 0.25 & 1 & 3 \\
\hline 12 & 3400 & 0.12 & 0.35 & 2 & 3 \\
\hline 13 & 3600 & 0.06 & 0.30 & 1 & 4 \\
\hline 14 & 3600 & 0.08 & 0.25 & 4 & 1 \\
\hline 15 & 3600 & 0.10 & 0.20 & 3 & 2 \\
\hline 16 & 3600 & 0.12 & & 4 & 3 \\
\hline
\end{tabular}

\subsection{EXPERIMENTAL PROCEDURE:}

Now as we have selected all the parameters and are ready to conduct the experiment. The experiment is to be carried on the Aluminium 6061-T6 alloy of diameter $(\phi) 20 \mathrm{~mm}$ and length $100 \mathrm{~mm}$. The turning is done on these work-pieces with dimensions, as per the experiment to the length of $50 \mathrm{~mm}$. The turning is done on the Jyothi CNC machine with a DNMG carbide coated tool. The machining is done on the CNC lathe using CNC part programming. The programming is done as according to the specifications. The fig shown below is the work-piece before machining.

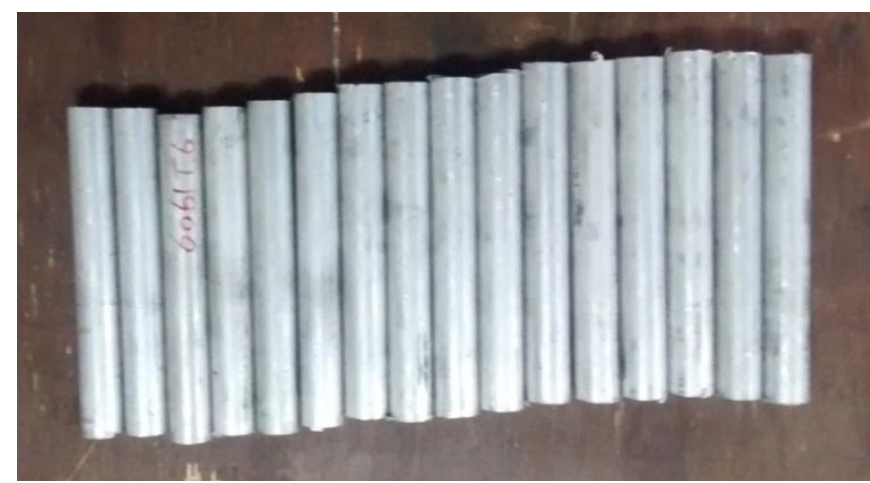

Figure 4.3 Work piece Material before Machining.

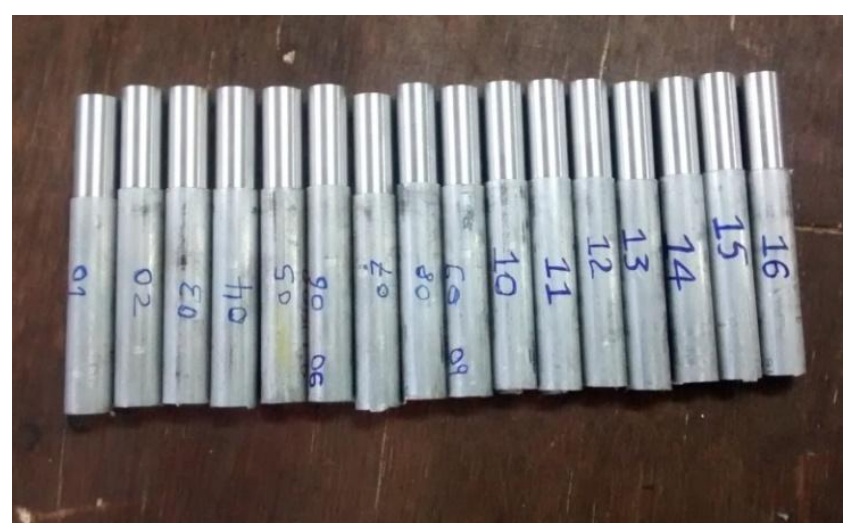

Figure 4.4 Work piece Material after Machining.

The responses obtained for the final experiment are as shown in the table. 


\subsection{MEASURMENT OF RESPONSES:}

The responses that are taken into account while conducting the experiment are the Surface roughness $\left(R_{\mathrm{a}}\right)$ and Material Removal Rate. The surface roughness is calculated using the surface roughness testing instrument in which the surface roughness testing instrument. The second response which is MRR is calculated using the mathematical equation by considering the machining time per each experiment. The material removal rate is given by.

$$
\operatorname{MRR}=\frac{\left[\mathrm{V}_{\mathrm{f}}-\mathrm{V}_{\mathrm{i}}\right]}{\mathrm{t}}
$$

Where

$\mathrm{V}_{\mathrm{f}} \rightarrow$ Final Volume of work-piece material

$V_{i} \rightarrow$ Initial Volume of work-piece material

$\mathrm{t} \rightarrow \mathrm{it}$ is the time taken for machining of each component

Table No 4.6- Parameters and their Responses.

\begin{tabular}{|c|c|c|c|c|c|c|}
\hline \multirow{2}{*}{ JOB NO. } & \multicolumn{3}{|c|}{ PARAMETERS } & \multicolumn{3}{c|}{ RESPONSES } \\
\cline { 2 - 7 } & SPEED & FEED & DOC & Ra $\mu \mathrm{m}$ & MRR $\mathrm{mm}^{3} / \mathrm{min}$ & ACC $(\mu \mathrm{m})$ \\
\hline 1 & 3000 & 0.06 & 0.20 & 0.886 & 1458.56 & 9 \\
\hline 2 & 3000 & 0.08 & 0.25 & 0.944 & 2776.38 & 26 \\
\hline 3 & 3000 & 0.10 & 0.30 & 1.418 & 2866.28 & 106 \\
\hline 4 & 3000 & 0.12 & 0.35 & 3.028 & 5212.64 & 32 \\
\hline 5 & 3200 & 0.06 & 0.25 & 0.754 & 2294.01 & 11 \\
\hline 6 & 3200 & 0.08 & 0.20 & 0.828 & 2366.24 & 30 \\
\hline 7 & 3200 & 0.10 & 0.35 & 1.327 & 5243.19 & 11 \\
\hline 8 & 3200 & 0.12 & 0.30 & 2.314 & 5122.14 & 30 \\
\hline 9 & 3400 & 0.06 & 0.30 & 0.958 & 2964.3 & 21 \\
\hline 10 & 3400 & 0.08 & 0.35 & 1.262 & 3429.72 & 73 \\
\hline 11 & 3400 & 0.10 & 0.20 & 1.146 & 5793.09 & 52 \\
\hline 12 & 3400 & 0.12 & 0.25 & 2.661 & 5015.2 & 62 \\
\hline 13 & 3600 & 0.06 & 0.35 & 1.136 & 3127.3 & 70 \\
\hline 14 & 3600 & 0.08 & 0.30 & 1.284 & 2463.04 & 61 \\
\hline 15 & 3600 & 0.10 & 0.25 & 1.306 & 3755.67 & 67 \\
\hline 16 & 3600 & 0.12 & 0.20 & 3.148 & 4030.79 & 22 \\
\hline
\end{tabular}

\section{DATA ANALYSIS OF THE EXPERIMENT}

\subsection{ANALYSIS OF VARIANCE (ANOVA):}

In this experiment we have used Analysis of variance (ANOVA) as the statistical tool for determining most influencing parameter on the response with an optimum combination of levels.

The below tables provide a complete analysis of variance.

\subsubsection{FOR SURFACE ROUGHNESS $\left(R_{\mathrm{a}}\right)$ :}

From the ANOVA, we have come to know that the most influencing parameter in the response table is the feed rate i.e the parameters which will mostly affect the surface roughness is the feed which is then followed by the speed and the depth of cut. So the optimum parameters that are found are.

1). Feed rate should be at the level 4 which is at $0.12 \mathrm{~mm} / \mathrm{rev}$.

2). Speed should be at the level 4 which is at 3600rpm.

3). DOC should be at the level which is at $0.35 \mathrm{~mm}$

The below table shows the ANOVA table for the experiment conducted for surface roughness.

Table No 5.1- ANOVA table for Surface Roughness.

\begin{tabular}{|c|c|c|c|c|c|}
\hline \multicolumn{7}{|c|}{ SURFACE ROUGHNESS } \\
\hline \multicolumn{5}{|c|}{ ANALYSIS OF VARIANCE FOR SN RATIO } \\
\hline SOURCE & DF & SS & MS & F & \% C \\
\hline SPEED & 3 & 12.366 & 4.122 & 12.70542 & 5.144868 \\
\hline FEED & 3 & 216.908 & 72.30267 & 222.8616 & 90.24447 \\
\hline DOC & 3 & 8.811 & 2.937 & 9.05284 & 3.665812 \\
\hline ERROR & 7 & 2.271 & 0.324429 & & \\
\hline TOTAL & 16 & 240.356 & & & \\
\hline
\end{tabular}


UGC Approved Journal

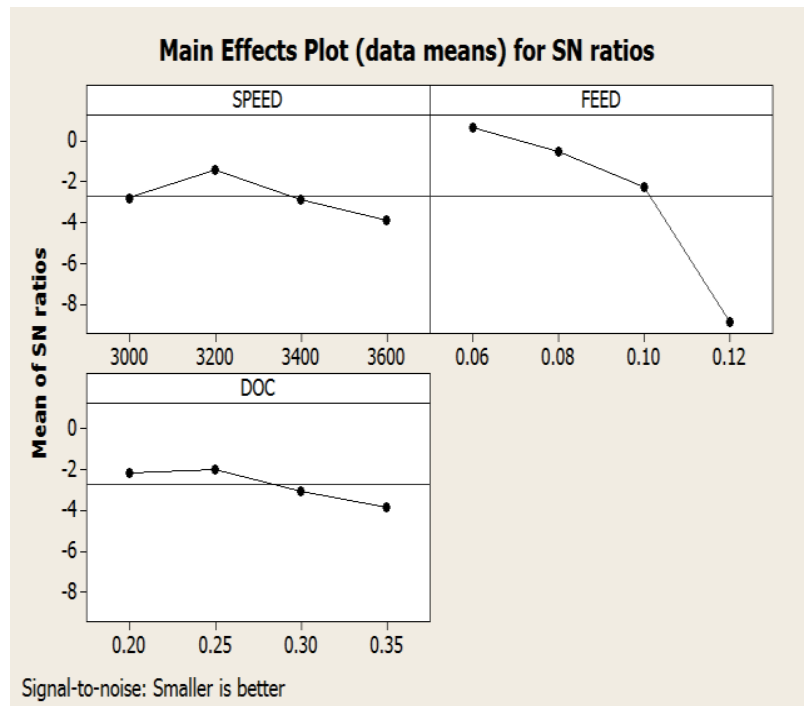

Figure No 5.1- Graph representing optimum parameters for Surface Roughness.

\subsubsection{FOR MATERIAL REMOVAL RATE (MRR):}

From the ANOVA, we have come to know that the most influencing parameter in the response table is the feed rate i.e. the parameters which will mostly effects the surface roughness is the feed which is then followed by the speed and the DOC. So the optimum parameters from which we can get the higher Material Removal Rate is as shown below.

1). Feed rate should be at the level 4 which is $0.12 \mathrm{~mm} / \mathrm{rev}$

2). Speed should be at the level 3 which is 3400rpm.

3). DOC should be at the level 4 which is $0.35 \mathrm{~mm}$

The below tables provide a complete analysis of variance for Material Removal Rate (MRR).

Table No 5.2- ANOVA table for Material Removal Rate.

\begin{tabular}{|c|c|c|c|c|c|}
\hline \multicolumn{6}{|c|}{ MATERIAL REMOVAL RATE } \\
\hline \multicolumn{6}{|c|}{ ANALYSIS OF VARIANCE FOR SN RATIO } \\
\hline SOURCE & DF & SS & MS & F & $\%$ C \\
\hline SPEED & 3 & 24.19 & 8.064 & 3.028326 & 14.47896 \\
\hline FEED & 3 & 106.65 & 35.549 & 13.34995 & 63.83552 \\
\hline DOC & 3 & 17.59 & 5.863 & 2.20177 & 10.52852 \\
\hline ERROR & 7 & 18.64 & 2.662857 & & 11.1570 \\
\hline TOTAL & 16 & 167.07 & & & \\
\hline
\end{tabular}

The graph shown below gives the SN ratio plot for the Material Removal Rate.

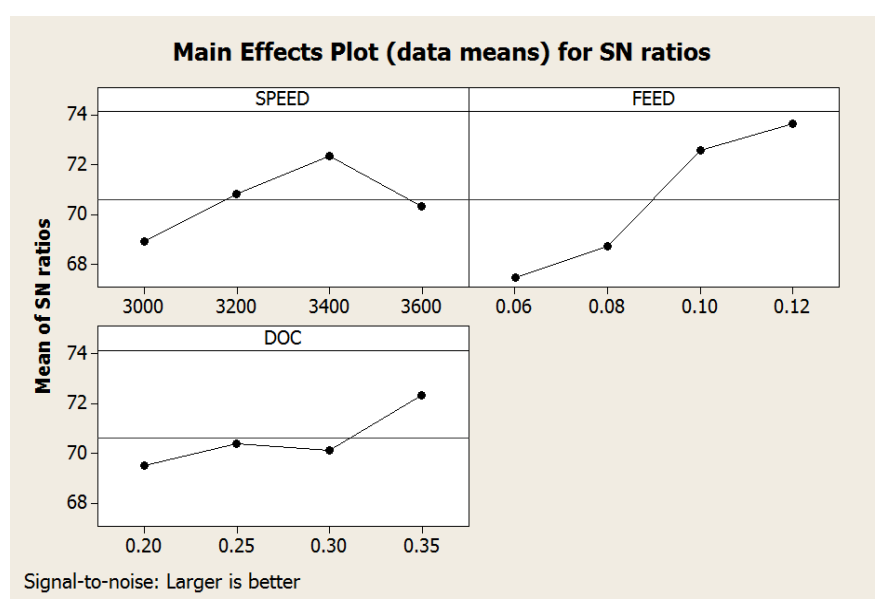

Figure No 5.2- Graph representing optimum parameters for Material Removal Rate. 


\subsubsection{FOR ACCURACY OF SURFACE ROUGHNESS:}

From the ANOVA, we have come to know that the most influencing parameter in the response table is the feed rate i.e. the parameters which will mostly effects the surface roughness is the speed which is then followed by the feed and the DOC. So the optimum parameters from which we can get the higher Material Removal Rate is as shown below.

1). Speed should be at the level 4 which is $3600 \mathrm{rpm}$.

2). Feed rate should be at the level 3 which is $0.10 \mathrm{~mm} / \mathrm{rev}$

3). DOC should be at the level 3 which is $0.30 \mathrm{~mm}$

The below tables provide a complete analysis of variance for the Accuracy of Measurement of surface roughness.

Table No 5.3- ANOVA table for Accuracy.

\begin{tabular}{|c|c|c|c|c|c|}
\hline \multicolumn{7}{|c|}{ ACCURACY } \\
\hline \multicolumn{7}{|c|}{ ANALYSIS OF VARIANCE FOR SN RATIO } \\
\hline SOURCE & DF & SS & MS & F & \%C \\
\hline SPEED & 3 & 201.11 & 67.03667 & 1.895757 & 41.06186 \\
\hline FEED & 3 & 133.12 & 44.37333 & 1.254851 & 30.56066 \\
\hline DOC & 3 & 65.69 & 21.89667 & 0.619225 & 20.14596 \\
\hline ERROR & 7 & 247.53 & 35.36143 & & 8.23152 \\
\hline TOTAL & 16 & 647.45 & & & \\
\hline
\end{tabular}

The graph shown below is the SN ratio graph for the Accuracy of surface roughness.

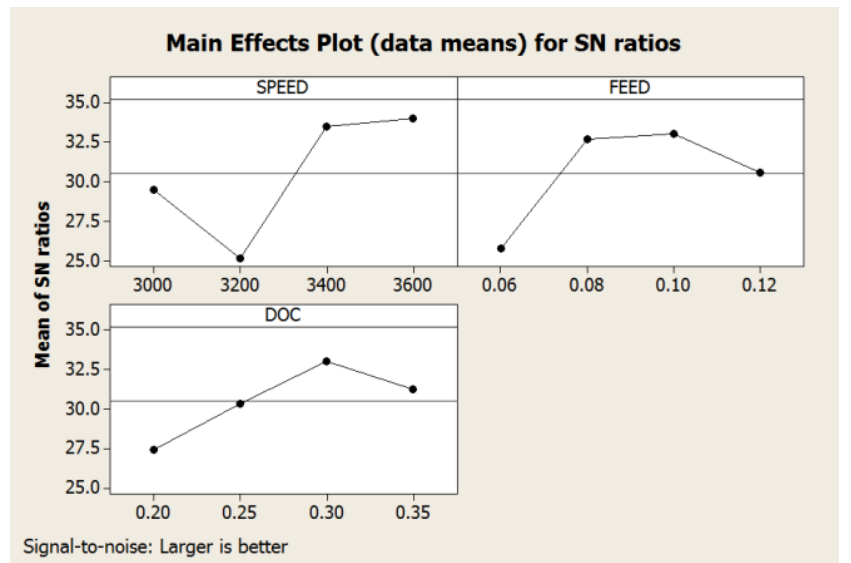

Figure No 5.3- Graph representing optimum parameters for Accuracy.

\section{CONFIRMATION TEST}

Confirmation test is carried out to check the whether the parameters that are obtained are optimum are not. An operation is carried out on the work-piece using the optimal parameters, for each optimal parameter an average of four experiments are carried out to obtain the predicted value.

The table below shows the conformation test for the Predicted value.

Table No 6.1- Conformation Test for Surface roughness.

\begin{tabular}{|c|c|c|c|c|c|}
\hline \multicolumn{4}{|c|}{ SURFACE ROUGHNESS } \\
\hline \multirow{2}{*}{ RESPONCES } & \multicolumn{3}{|c|}{$\begin{array}{c}\text { INITIAL FACTOR } \\
\text { SETTING }\end{array}$} & \multicolumn{2}{c|}{ OPTIMAL CONDITIONS } \\
\cline { 2 - 6 } & $\begin{array}{c}\text { SPEED } \\
(\mathrm{rpm})\end{array}$ & $\begin{array}{c}\text { FEED } \\
(\mathrm{mm} / \mathrm{rev})\end{array}$ & $\begin{array}{c}\text { DOC } \\
(\mathrm{mm})\end{array}$ & $\begin{array}{c}\text { PREDICTED } \\
\text { VALUES }\end{array}(\mu \mathrm{m})$ & $\begin{array}{c}\text { EXPERIMANTAL VLAUES } \\
(\mu \mathrm{m})\end{array}$ \\
\hline $\begin{array}{c}\text { Surface } \\
\text { Roughness }\end{array}$ & 3600 & 0.12 & 0.35 & 1.416 & 1.752 \\
\hline
\end{tabular}


UGC Approved Journal

Table No 6.2- Conformation Test for Material Removal Rate.

\begin{tabular}{|c|c|c|c|c|c|}
\hline \multicolumn{4}{|c|}{ MARETIAL REMOVAL RATE } \\
\hline \multirow{3}{*}{ RESPONCES } & \multicolumn{3}{|c|}{$\begin{array}{c}\text { INITIAL FACTOR } \\
\text { SETTING }\end{array}$} & \multicolumn{2}{c|}{ OPTIMAL CONDITIONS } \\
\cline { 2 - 6 } & $\begin{array}{c}\text { SPEED } \\
(\mathrm{rpm})\end{array}$ & $\begin{array}{c}\text { FEED } \\
(\mathrm{mm} / \mathrm{rev})\end{array}$ & $\begin{array}{c}\text { DOC } \\
(\mathrm{mm})\end{array}$ & $\begin{array}{c}\text { PREDICTED } \\
\text { VALUES } \mathrm{mm}^{3} / \mathrm{min}\end{array}$ & $\begin{array}{c}\text { EXPERIMANTAL } \\
\text { VLAUES } \mathrm{mm}^{3} / \mathrm{min}\end{array}$ \\
\hline Material Removal Rate & 3400 & 0.12 & 0.35 & 3767.5 & 3547.2 \\
\hline
\end{tabular}

Table No 6.3- Conformation Test for Accuracy

\begin{tabular}{|c|c|c|c|c|c|}
\hline \multicolumn{9}{|c|}{ ACCURACY } \\
\hline \multirow{2}{*}{ RESPONCES } & \multicolumn{2}{|c|}{ INITIAL FACTOR SETTING } & \multicolumn{2}{c|}{ OPTIMAL CONDITIONS } \\
\cline { 2 - 7 } & $\begin{array}{c}\text { SPEED } \\
(\mathrm{rpm})\end{array}$ & $\begin{array}{c}\text { FEED } \\
(\mathrm{mm} / \mathrm{rev})\end{array}$ & $\begin{array}{c}\text { DOC } \\
(\mathrm{mm})\end{array}$ & $\begin{array}{c}\text { PREDICTED } \\
\text { VALUES }\end{array}(\mu \mathrm{m})$ & \multicolumn{2}{|c|}{ EXPERIMANTAL } \\
VLAUES & $(\mu \mathrm{m})$ \\
\hline Accuracy & 3600 & 0.10 & 0.30 & 48.67 & 52.74 \\
\hline
\end{tabular}

\section{CONCLUSION}

The experiment was carried out using L16 orthogonal array which is based on Taguchi a Design. Here Spindle Speed, Feed rate and Depth of Cut are the main input parameters form which the output parameters such as Surface Roughness, Material Removal Rate and accuracy are optimized. The Taguchi method coupled with Grey Relational Analysis used for solving multi optimization criteria.

We have found the following Conclusion based on the experimentation results.

1. From the experiment conducted by L16 orthogonal array, using ANOVA as the statistical tool we have found that feed is the most significant parameter on surface roughness with $90.24 \%$ of contribution, which is then followed by speed $5.14 \%$ and at last depth of cut $3.66 \%$ contribution

2. The parameter that is most effective during material removal rate is feed rate with $63.83 \%$ of contribution and spindle speed and feed rate with minimal of $14.47 \%$ and $10.52 \%$ of contribution respectively.

For accuracy it is found that spindle speed is the most affective parameter with $41.06 \%$ of contribution and followed by feed rate of $30.56 \%$ and depth of cut of $20.14 \%$ of contribution

\subsection{FUTURE SCOPE:}

Based on the present work there are considerable amount of possibilities for future scope and they are given below.

1. The experiment can further carryout by varying the parameters so that we could optimize the output results to higher extent.

2. Linear co-relation and regression can be used to create a mathematical model for the optimization of output parameters.

3. Principle component analysis, discriminate analysis and multi-correspondence can be used for more accurate results.

\section{REFERENCES}

1. Ranganath M.S. al. "optimization of surface roughness in CNC Turning of Aluminum 6061 using Taguchi technique" International Journal of Innovative Research in Science, Engineering and Technology. Vol. 5, Issue 5, May 2015

2. Nikunj V. Patel. al. "selection of tool insert in CNC Turning process using MADM method". International Journal of Engineering and Advanced Technology, Volume-1, Issue-5, June 2012.

3. Krupal Pawar. al. "multi-objective optimization of CNC Turning Process parameters for High Speed Steel (M2) using Taguchi and ANOVA method". International Journal of Hybrid Information Technology Vol.8, No.4 (2015), pp.67-80.

4. G.Hainath Gowd. at. "Optimal selection of machining parameters in CNC turning process of EN-31 using intelligent hybrid decision making tool". International Journal of Emerging Research in Management \&Technology (Volume-3, Issue-8), GCMM 2014.

5. D.M. D'Addona. at. "Analysis of surface roughness in hard turning using wiper insert geometry". International Journal of Engineering Research \& Technology Vol. 2 Issue 12, December - 2013

6. Basil M. Eldhose. at. "Optimization of cutting parameters of SS 304 for CNC turning operation". International Journal of Emerging Engineering Research and Technology Volume 1, Issue 8 (September 2014).

7. Nand Kumar. al. "surface finish monitoring in CNC Turning using RSM and Taguchi Technique". International Journal of Innovative Research in Advanced Engineering Volume 4, Issue 9 (September 2014)

8. Vitor Augusto A.de Godoy. al. "turning of interruption and continuous hardened steel surface using ceramics and CBN cutting tools". International Journal of Advanced Engineering Research and Studies. Journal of material processing technology (2011) 